Path. Microbiol. 1975;42:201

\title{
Professor A. Grumbach 1895-1975
}

Arthur Grumbach ist am 22. November 1975 gestorben. Seine Le-bensdaten und seine vielen Verdienste (um die Schweizerische Gesell-schaft für Mikrobiologie, die Schweizerische Gesellschaft für Allergie und Immunologie sowie um diese Zeitschrift, die er gründen half) sind schon früher gewürdigt worden. Vor kurzem haben wir seinen achtzigsten Ge-burtstag gefeiert. Er war damals von den vielen Zeichen der Anteilnahme gerührt und hat es sich nicht nehmen lassen, durch ein Kärtlein alien zu danken, die seiner gedacht hatten. Er mag uns so in Erinnerung bleiben, als ein urbaner Mensch, dem Höflichkeit ein inneres Bedürfnis war, der aber nie mit seiner Meinung zurückhielt, wenn sie ihm richíig schien.

Im Namen der Redaktion J. Lindenmann

Mit dem Hinscheiden von Herrn Professor A. Grumbach betrauern wir nicht nur den Verlust eines bedeutenden Forschers und eines Mit-gründers und langjährigen Redaktors unserer Zeitschrift, sondern auch den eines warmherzigen Freundes, der uns in guten und schlechten Zeiten immer mit seinem klugen Rat zur Verfügung gestanden hal.

Thomas Karger 